\title{
Strategies for reducing medication errors in the emergency department
}

\author{
This article was published in the following Dove Press journal: \\ Open Access Emergency Medicine \\ 23 July 2014 \\ Number of times this article has been viewed
}

\author{
Kyle A Weant ${ }^{1}$ \\ Abby M Bailey ${ }^{2}$ \\ Stephanie N Baker ${ }^{2}$ \\ 'North Carolina Public Health \\ Preparedness and Response, North \\ Carolina Department of Health \\ and Human Services, Raleigh, NC, \\ ${ }^{2}$ University of Kentucky HealthCare, \\ Department of Pharmacy Services, \\ Department of Pharmacy Practice \\ and Science, University of Kentucky \\ College of Pharmacy, Lexington, \\ KY, USA
}

\begin{abstract}
Medication errors are an all-too-common occurrence in emergency departments across the nation. This is largely secondary to a multitude of factors that create an almost ideal environment for medication errors to thrive. To limit and mitigate these errors, it is necessary to have a thorough knowledge of the medication-use process in the emergency department and develop strategies targeted at each individual step. Some of these strategies include medicationerror analysis, computerized provider-order entry systems, automated dispensing cabinets, barcoding systems, medication reconciliation, standardizing medication-use processes, education, and emergency-medicine clinical pharmacists. Special consideration also needs to be given to the development of strategies for the pediatric population, as they can be at an elevated risk of harm. Regardless of the strategies implemented, the prevention of medication errors begins and ends with the development of a culture that promotes the reporting of medication errors, and a systematic, nonpunitive approach to their elimination.
\end{abstract}

Keywords: emergency medicine, pharmacy, medication errors, pharmacists, pediatrics

\section{Introduction}

An adverse drug event (ADE), defined as any injury resulting from drug-related administration, is estimated to occur in the US 1.5 million times annually, making it one of the most costly and common sources of preventable harm. It also comes at an expense of $\$ 3.5$ billion annually for in-hospital occurrences in the US. ${ }^{1}$ A medication error is any error in the medication process, regardless of whether a patient experiences an adverse consequence. ${ }^{2-4}$ Not all ADEs are caused by a medication error, and not all medication errors result in an adverse event. ${ }^{5}$ Furthermore, it is important to recognize that not all ADEs can be prevented. For example, it is impossible to predict if a patient exposed to a new drug will develop a rash as a result. Some drugs also have exceedingly rare side effects that may not present themselves during premarketing trials, and only become apparent after millions of diverse individuals have received them. ${ }^{6}$ Medication errors such as this occur most commonly during the ordering and administration phases, occurring in up to $82 \%$ and $7 \%$ in some studies, respectively. 7,8 These errors can take many forms (eg, wrong dose, wrong drug delivered or prescribed, known allergy, wrong time or route, or missed dose); however, dosing errors are by far the most frequent, constituting between $40 \%$ and $50 \%$ of all errors. ${ }^{7}$ It is the aim of this manuscript to provide a comprehensive review of the etiology of medication errors in the emergency department (ED) setting and mitigation strategies for reducing errors in any ED practice setting.
Correspondence: Kyle A Weant North Carolina Public Health Preparedness and Response, North Carolina Department of Health and Human Services, 100 East Six Forks Road - Suite 150, Raleigh,

NC 27699-1900, USA

$\mathrm{Tel}+\mathrm{I} 8593386622$

Fax + I 91957| 6786

Email kaw9600@alumni.unc.edu submit your manuscript | www.dovepress.com

Dovepress

http://dx.doi.org// 0.2/47/OAEM.S64174 


\section{At-risk environment}

The ED experiences a high frequency of medication errors, with estimates of medication-error rates varying from $4 \%$ to $14 \%$ to as high as $39 \%$ in pediatric ED settings. ${ }^{9}, 10$ In addition, approximately $3 \%$ of all hospital-related adverse events occur in the ED. ${ }^{11}$ The etiology of these events is multifactorial (Table 1). ${ }^{6}$ Patients who present to the ED tend to be previously unknown to the practitioners, often there is little to no immediate access to medical records, and those with that knowledge are usually unavailable. In many cases, it is necessary to dispense and administer drugs when pharmacists are unavailable for important safety checks. This is further exacerbated by those EDs that dispense outpatient supplies to patients who cannot afford their medications or when local pharmacies are not open, and thus errors in dispensing may go completely unnoticed as the patient returns home and is not monitored. The critical nature of many ED patients provides yet another opportunity for medication errors. National ED overcrowding limits adequate staffing capabilities, resulting in an increased reliance on verbal orders, which have the inherent risk of being misinterpreted or misunderstood. A survey of ED nurses described several perceived barriers to following recommendations for safe medication use, including the absence of standardized handoff communication, failure to use read-backs for verbal orders, and lack of independent double checks of nurse-prepared intravenous infusions. ${ }^{12}$ Further contributing to these high rates of errors is the fact that more than three-quarters of ED visits are associated with a medication being prescribed or administered, representing more than 210 million medication encounters annually in the US. ${ }^{13}$ Fortunately, in the US, over $95 \%$ of ED medication errors do not result in patient harm. ${ }^{14}$

Pediatric patients presenting to the ED are particularly at risk for medication errors, with rates found to be as high as 5.7 medication errors per 100 orders. ${ }^{15}$ The Institute of Medicine (IOM) has noted that this is largely due to the fact that ED staff members are often quite unfamiliar with the unique needs of pediatrics and that there is a paucity of research studies addressing medical errors in pediatrics. ${ }^{16}$ The most common type of medication error in the pediatric emergency-medicine population is an overdose. ${ }^{17}$ When dosing errors occur in pediatric patients, its proportional impact can be quite staggering, as they have the additional risk of receiving toxic doses. ${ }^{18,19}$ In a small child, a tenfold dosing error may be administered in a single syringe, and may not provide the nurse with the same visual cue to the error as making the same error in an adult that would require 10 prefilled syringes..$^{20}$ It is important to assess critically the medications that are routinely administered to children in the ED. ${ }^{21}$
Several investigations have attempted to detail further the etiologies of medication errors in the ED and thus ascertain possible mitigation strategies..$^{5,9,22,23}$ In one study of anonymous errors reported via a national, confidential medication error-reporting program across $496 \mathrm{EDs}$, a total of 13,932 medication errors were reported over a 4-year time span. This translates to an error rate of 78 reports per 100,000 patient visits. ${ }^{14}$ The groups most frequently responsible for these errors were physicians (24\%) and nurses (54\%). The most common errors that occurred were in the administration phase (36\%), and the most common type was improper dose/quantity (18\%). Leading causes of errors were "not following procedure/protocol" (17\%) and "poor communication" (11\%), whereas contributing factors were "distractions" (7.5\%), "emergency situations" (4.1\%), and "workload increase" (3.4\%). Actions detailed by the reporter that were taken as a result of the errors included "informing the staff member who committed the error" (26\%), "enhancing the communication process" (26\%), and "providing additional education or training" (12\%). Therefore, we see a process that is at high risk for errors, affects all practitioners, and has multiple contributing factors.

\section{Stages of the prescribing process}

This high frequency of medication usage, the environmental challenges in the ED, and a highly complex medication-use process provide for an almost-"perfect storm" for medication errors. ${ }^{2,24}$ To develop strategies to target the prevention of medication errors fully, it is necessary to have a solid understanding of the medication-use process in the ED and how each stage contributes to the overall error rate. Drug ordering and delivery are typically broken into five different stages: A, prescribing; B, transcribing; $\mathrm{C}$, dispensing; D, administration; and E, monitoring (Figure 1). Each of these stages represents a possible risk point and a potential vulnerable link in the patient-safety chain.

\section{Prescribing stage}

The prescribing stage is one of the stages where medication errors occur most frequently, representing $71 \%$ of serious medication errors. ${ }^{25}$ The most common factors associated with errors at this stage have been cited as lack of knowledge pertaining to both the drug prescribed and the patient for whom the drug is prescribed. ${ }^{26,27}$ Contributing to the rate of medication errors at this stage in the ED is the previously mentioned reliance on verbal orders. Utilization of a verbal process at this stage can turn even a correct order into a medication error if it is misunderstood or misinterpreted. 


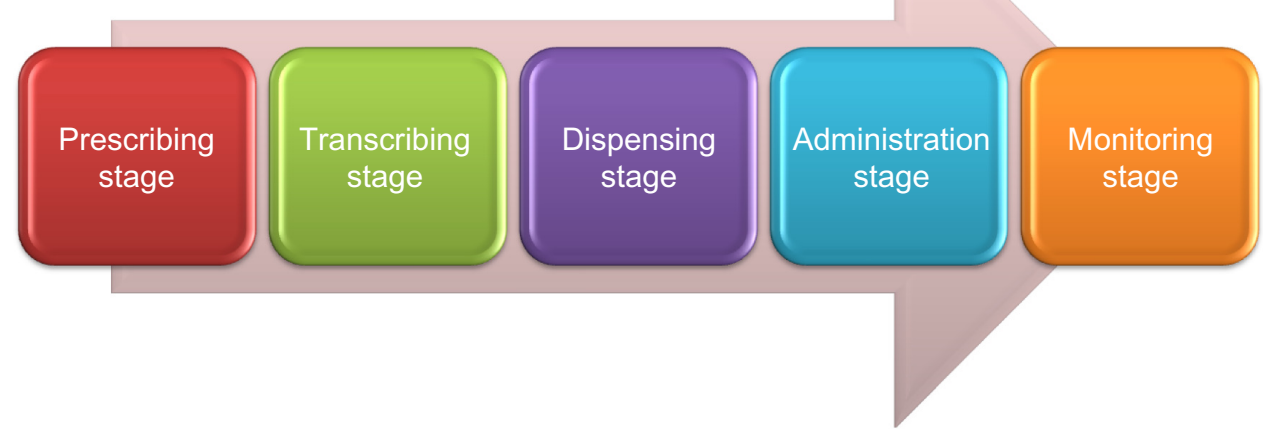

Figure I Emergency department medication-use process.

Note: Data from Peth. ${ }^{6}$

\section{Transcribing stage}

Transcription errors occur when a communication issue occurs between the prescriber and the individual dispensing or administering the medication. ${ }^{6}$ These can develop from handwriting errors, but can also be secondary to unclear or misinterpreted orders. The uniqueness of transcribing errors lies in the fact that they are due to communication failures rather than knowledge opportunities; they are $100 \%$ preventable. The use of computerized provider-order entry (CPOE) systems can essentially eliminate the occurrence of these errors by having providers enter medication orders directly into the system. ${ }^{28}$ Some contributing factors to these errors include the multitude of names, dosage forms, and strengths of various agents. Soundalike medications and abbreviations also provide a significant obstacle to eliminating these errors as well.

\section{Dispensing stage}

This is the process of providing the medication to the practitioner who will be administering the medication. ${ }^{6}$ The key player at this stage is the pharmacist. ${ }^{29,30}$ In addition, in many EDs, automated dispensing cabinets fill the key role of dispensing for urgent and emergent medications. In some circumstances, particularly in EDs that dispense medications directly from the ED after hours, the final safety check by the pharmacist is circumvented.

\section{Administration stage}

The act of physically administering the drug to the patient represents the very last moment providers can catch errors before they can do harm. ${ }^{6}$ Nurses are absolutely critical personnel at this stage. These errors typically arise when the wrong drug is administered, or the right drug is administered in the wrong dose, via the wrong route, or with an incompatible coadministered drug. ${ }^{6}$ This can also occur when the right drug is given to the wrong patient. ${ }^{31}$

\section{Monitoring stage}

This stage involves the activities following administration of a medication and observing the impact of pharmacotherapy. It can be particularly challenging to monitor patients for efficacy, side effects, and toxicities in busy EDs where multiple medications are administered to patients in a rapid and emergent fashion. This is not only within the traditional sense of monitoring on the inpatient side but also includes patients discharged to home and ensuring that appropriate follow-up occurs. It is important that patients are given adequate discharge instructions and are counseled on potential self-monitoring techniques, as well as any possible harmful side effects that may occur.

\section{Medication error-prevention strategies}

To decrease the occurrence of medication errors, it is important to work toward developing strategies to combat the risk of medication errors at all steps in the medicationuse process. A PubMed search (1966-January 2014) was conducted combining the terms "medication errors" and "emergency department" for the identification of publications outlining such strategies. Reference lists of relevant articles were also reviewed to identify articles that may have been missed in the initial search. Articles were excluded if they were not in English. The relevant strategies identified from this research included medication-error analysis, computerized provider-order entry systems, automated dispensing cabinets, bar-coding systems, medication reconciliation, standardizing medication-use processes, education, and emergency-medicine clinical pharmacists. 


\section{Medication-error analysis}

Medication-error reporting is an essential aspect of limiting medication-error occurrence and the development of medication error-prevention strategies. ${ }^{32}$ Despite the profound impact that these errors have on the system, they largely go underreported, largely due to the fear of repercussions. ${ }^{33}$ Although challenging, medication errors should be viewed as valuable learning exercises to improve care and limit their recurrence, and hospital management should avoid taking punitive action against individuals involved in medication errors, as this discourages reporting and limits learning opportunities. Every medication error that goes unreported represents an error that will continue to be replicated and continue to put patients at risk. Errors that are reported allow for the development of potential countermeasures to either eliminate them altogether or mitigate their impact. The large majority of errors are the result of defects that exist within the underlying systems of practice rather than within human practitioners, as they merely serve as the vessel by which these shortcomings are manifested. ${ }^{34}$ Although the elimination of medication errors should be the goal of any organization, it is important to recognize that the occurrence of medication errors is an inevitable part of clinical practice..$^{34}$

It is critical that the systems that expose patients to potential medication errors be evaluated in a systematic and critical fashion. ${ }^{6}$ To maximize the learning potential of medication errors, standardizing the process of reporting and classification is important in order to gauge the severity and contributing factors of errors appropriately. The severity of medication errors is often determined utilizing the National Coordinating Council for Medication Error Reporting and Prevention. ${ }^{35}$ There are multiple avenues for documenting medication errors and ADEs, including the MEDMARX registry and the Institute for Safe Medication Practices (ISMP) ${ }^{36,37}$ Regardless of the system used, it is

Table I Variables associated with medication errors in the emergency department

Undifferentiated and unfamiliar patients

24-hour nature of services

Dispensing and administering medications without pharmacist double checks

Outpatient medication dispensing without pharmacist double checks Critical and emergent nature of care provided

Overcrowding

Reliance on verbal orders

Understaffing of personnel

Absence of standardized handoff communication

Lack of independent double checks of nurse-prepared medications

Note: Data from Peth. ${ }^{6}$ imperative for institutions to encourage reporting, ensure systematic classification and description, and complete the care-improvement loop with adequate follow-up.

It is also important to remain up to date on medication errors both within a specific institution and nationally. Regardless of the medication error-reporting system utilized, it is advantageous to have it automatically generate email reports to necessary parties in real time. The ISMP and US National Coordinating Council on Medication Error Reporting and Prevention have created a National Alert Network to notify health care providers of errors that have recently caused serious harm and death, so that institutions can proactively prevent them from happening in their hospitals. ${ }^{38}$

Instituting a systematic approach to analyzing medication errors received can take several forms. Although none of these approaches have been specifically evaluated in the ED, they are potentially applicable in any health care setting. It is often advantageous to stop a practice, if possible, when a problem occurs and correct it as soon as possible. Convening a group of key players quickly to assess what happened, contributing factors, and corrective actions that can be taken to prevent its recurrence can greatly facilitate medicationerror prevention. Multiple analysis techniques are available for this process. One retrospective error-analysis approach is known as root-cause analysis..$^{39,40}$ This process is initiated when an untoward event occurs that stimulates analysis. A multidisciplinary team then works to analyze all aspects of this event through its sequential re-creation. A limitation of this approach is that it is largely directed at characterizing and preventing specific errors rather than assessing the vulnerabilities that may exist throughout the medication-use process. On the opposite end of the spectrum is a technique known as failure-mode and effects analysis. ${ }^{40,41}$ This approach is a more proactive one that targets the identification of larger system-level weaknesses prior to their contributions to medication errors. This is typically conducted by a multidisciplinary committee that identifies an error-prone process and then goes about reviewing that process from beginning to end, isolating failure modes and then categorizing them into the order in which they should be addressed. While this process has some advantages over the selective nature of root-cause analysis, it is somewhat hampered by its extremely timeintensive process. While both can be effective, a root-cause analysis approach may be more feasible for practitioners in a busy ED.

Some institutions have documented success in improving processes and reducing medication errors through the use of Lean Sigma methodology. ${ }^{42}$ This process utilizes extensive 
process mapping to study and redesign processes, with the intent of eliminating non-value-added activities. Utilizing these concepts to improve medication-administration safety, one general hospital study noted a significant reduction of safe-practice violations by 42 violations per 100 doses and significantly reduced medication errors from 10.3 errors per 100 doses to 2.8 errors per 100 doses. ${ }^{43}$ These results represented the compilation of six different lean-concept modifications, thus making it challenging to ascertain which alternatives yielded the greatest impact on patient safety. Nevertheless, this does show that detailed review of processes and traditional practice has the potential to yield results. In a busy practice site, such as the ED, with a high rate of errors, such reviews could yield significant results.

\section{Computerized provider-order entry systems}

CPOE systems seek to eliminate errors resulting from handwritten and verbal orders by having providers enter medication orders directly into the computer system. ${ }^{28}$ Additional advantages of this approach are the integration of clinical decision-support systems (CDSSs) that assist the provider with choosing the appropriate medications and doses, as well as comparing and contrasting that with the patient's medical history, concomitant medications, and allergy history. The functions included can incorporate drug-allergy checking, antimicrobial stewardship, dosing guidance, guideline compliance, formulary decision support, and checking for duplicate therapies and drug-drug interactions. One study looking at prescribing errors in a pediatric emergency department developed a pediatric medication "quicklist" that was added to the CPOE system. The authors found that when this list was used, the error rate dropped from 18.3 errors per 100 orders to 1.9. They also found that errors of wrong formulation, allergy, drug-drug interaction, and rule violations were eliminated. The limitation of this study, however, was the fact that the quicklist was used only $30 \%$ of the time. ${ }^{44}$ Advanced systems may also offer recommendations for renal insufficiency, geriatric patients, lab testing, and drug-disease contraindication checking. Utilizing representatives from multiple disciplines to help build and design CDSSs can greatly facilitate the development of efficient and optimal systems. The use of a CPOE system with a CDSS is recommended by the IOM, and is associated with a $70 \%$ reduction in ADEs in primary care and a 50\% reduction in dispensing errors from pharmacies. ${ }^{45} \mathrm{CPOE}$ systems are associated with a $20 \%$ reduction in hospital-wide mortality and improvement in complying with measures, including acute myocardial infarction, chronic heart failure, and pneumonia. ${ }^{46,47}$ Furthermore, leveraging this technology to be an active participant in patient care through the notification of health care providers utilizing automatic paging and other systems of specific patients, disease states, and medication orders can further optimize and expedite care.

As with any technological intervention, it is only as good as its design and programming. Despite the documented positive results of CPOE implementation, there have been some less than positive unintended consequences as a result. ${ }^{48-50}$ In a national study of ED medication errors, multiple errors associated with CPOE systems were noted. ${ }^{14}$ In this analysis of non-computer-entry errors versus computer-entry errors, errors caused by CPOE were less likely to involve nurses $(55 \%$ versus $20 \%$ ) and more likely to involve physicians and pharmacists (23\% versus $49 \%$ and $3 \%$ versus $8 \%$, respectively). CPOE errors were more likely to have occurred at the prescribing phase (29\% versus 61\%) and less likely to have occurred during the administration phase (37\% versus 10\%). Errors associated with CPOE were more likely to be due to improper dose/quantity (17\% versus $28 \%$ ), wrong patient (4\% versus $12 \%)$, and wrong dosage ( $1 \%$ versus $8 \%$ ). Errors associated with CPOE were more likely to have never reached the patient (category B, 39\% versus 56\%) and less likely to have reached the patient (category C, 34\% versus $25 \%$ ) or required monitoring/intervention (category D, 10\% versus 4\%). Although this study was limited by the fact that it was a voluntary self-reported database and thus underestimated the actual number of errors, it does represent the best-available insight currently regarding CPOE-associated errors. Therefore, while both CPOE and CDSS systems can eliminate handwriting errors altogether and may go a long way toward mitigating several other misadventures, it is important to note that these systems alone are not the entire answer. It is imperative that institutions remain vigilant with regard to updating, improving, and tailoring these systems to fit each institution's unique needs and style of practice. It is also important to keep in mind that in a busy ED where the majority of orders are verbal, even the best CPOE and CDSS safeguards may be circumvented.

\section{Automated dispensing cabinets}

Automated dispensing cabinets (ADCs) are common in ED settings, and are drug-storage devices that allow for medications to be stored and dispensed by a computer at the point of care. These have largely replaced the medication cabinets or carts that were previously used for this purpose. This technology has multiple benefits, including allowing for the profiling of patients and thus the review of medication orders by a 
pharmacist prior to medication administration, a reduction in time to retrieve medications for patient use, and real-time inventory tracking. Despite the additional safeguards that this technology offers, it is important for practitioners to recognize that the dispensing device does not eliminate the opportunity for error and can actually contribute to medication errors. ${ }^{51}$ These errors largely center around medication-retrieval errors involving the selection of the wrong medication or dose and errors associated with restocking the ADC with the incorrect medication. Potential errors such as these can be limited by placing medications not needed in an emergency manner in the hospital pharmacy to ensure that a double check occurs prior to obtaining them. ${ }^{9}$ Health care practitioners are encouraged to collaborate with pharmacists in the event of detecting a misfill and not abdicate any professional responsibilities when retrieving medications from such devices. Confirmation that the product and strength at the point of drug retrieval is accurate should occur and be repeated at the point of administration. Guidelines for the safe use of ADCs have been developed by both American Society of Health-System Pharmacists and ISMP, and should be incorporated into practice at all institutions. ${ }^{37,52}$ Due to the required speed with which care must be provided in the ED, often ADCs in this area are placed on an "override" status, thus allowing for any medication to be removed for any patient. Although in many ways this may facilitate care, it also has the potential to put some patients at increased risk by eliminating important safeguards. It is important for institutions to continually reassess this practice and ensure that the risks of this practice are minimized and the benefits are realized.

\section{Bar-coding systems}

Bar-code medication-administration systems work by placing a unique identifier on each medication and every patient. This allows for patient, medication, and employee identification codes to be scanned automatically to ensure that the right patient, drug, dose, route, and time are correct prior to administration. ${ }^{28}$ The greatest impact of this technology on reducing medication errors is in the administration phase of the drug-use process. Scanning of the medication allows the nurse to identify errors in drug, dose, or dosage form prior to medication administration. ${ }^{53}$ It also assists in ensuring compliance with Joint Commission recommendations for the consistent use of two patient identifiers. ${ }^{54}$ Hospital-wide data have shown that bar-coding can eliminate transcription errors, reduce $50.8 \%$ of potential ADEs, and reduce $27.3 \%$ of timingadministration errors. ${ }^{55}$ Due to these significant benefits in patient safety, the US Food and Drug Administration issued a rule requiring bar-code labeling in early 2004 for prescription drugs, biological products, and over-the-counter drugs that are commonly used in hospitals. ${ }^{6}$ Often, however, this system is circumvented, as hospitals purchase medications in bulk and repackage them into individual units of use for specific patients. This then requires them to be relabeled with another bar code, which has the potential to generate errors.

In one hospital study, the most frequent cause of bar code-related errors was mislabeling, contributing to $27 \%$ of errors. ${ }^{53}$ This typically resulted when the dispensed product was labeled with the bar code of another product or labeled with the wrong strength or dosage form. These most commonly were caused by lookalike or soundalike products. Although these errors can be captured by astute nursing personnel, false confidence in technology can lead to the perpetuation of the medication error. These errors can be reduced by implementing additional label checks by both pharmacy personnel and nurses at the bedside prior to medication administration.

\section{Medication reconciliation}

It has been well documented that the transition of care on admission to the hospital and between clinical areas is a risk point for medication errors. ${ }^{28}$ Medical and allergy histories, data on current medications, and complete information on concomitant disease states are frequently unavailable to ED professionals, and often there is limited access to records in the ED. Medication discrepancies occur frequently on admission to EDs, with at least $60 \%$ of patients admitted to the hospital on various services having at least one discrepancy regarding their home regimen and admission orders. ${ }^{56-58}$ The most common error is omitting a medication being taken at home. ${ }^{58,59}$ Systems should be developed and built to obtain the most accurate and complete medical and medicationhistory lists possible. Emergency medical services personnel and ED staff should encourage patients and family members to bring all of their medications to the ED. When possible, primary care physicians and pharmacies should be consulted regarding medications and medical histories.

Obtaining an accurate medication history is the first step in attempting to decrease hospital admission-related errors, and is considered an essential component of safe and effective medical practice. A multitude of factors have been identified as contributing to the success or failure of obtaining an accurate medication history, including: 1) the time available for interview, 2) language barriers, 3) illness severity, 4) cognitive status, and 5) the patient's familiarity with his or her medication regimen. ${ }^{57}$ The Joint Commission on Accreditation of 
Healthcare Organizations in the US has defined medication reconciliation as the process of comparing a patient's medication orders to all the medications that the patient has been taking, and has listed it as a 2014 medication-related National Patient Safety Goal. ${ }^{60}$ The reconciliation of these medications should assist in avoiding medication errors, such as omissions, duplications, dosing errors, or drug interactions. Ideally, this reconciliation should occur on entry to the institution and at every transition-of-care point, including changes in setting, service, practitioner, or care level.

The Institute for Healthcare Improvement proposes three generic steps for completion of this process: 1) verification, where the medication history or list is collected; 2) clarification, where medications and dosages are checked for appropriateness; and 3) reconciliation, where any changes are documented. This process has been shown to eliminate most medication errors at intensive care unit transfer and decreased medication discrepancies at discharge from 1.44 errors per patient to $1.05 .^{61,62}$ The importance of including the patient in the reconciliation process has been recommended, and increased the detection of discrepancies at discharge from 2.7 to 5.3 per patient in one study. ${ }^{63}$

\section{Standardizing medication-use processes}

The standardizing of the processes of medication ordering and administration has been suggested as one modality for limiting medication errors, including labeling and equipment inventory, such conventions as limited and formally structured verbal order processes, and limited access to high-alert medications. ${ }^{32}$ The use of unit-dose packaging eliminates the need for calculations at the point of care, and thus reduces dosage errors, overall medication-error rates, and timingadministration errors in hospitals from $24.3 \%$ to $9.7 \%$ compared with a ward stock-distribution system. ${ }^{64}$ Also, instituting a system of standardized concentrations for intravenous infusions is recommended by the ISMP. ${ }^{65}$ Labeling adjustments, such as "tall man" lettering, has been an effective way to differentiate drugs with similar names by capitalizing differing letters (eg, DOBUTamine, DOPamine, hydrALAZINE, hydrOXYzine). ${ }^{66,67}$ Furthermore, the labels of all products used in the ED setting must be unobstructed, designed in a clear way, and verified before medication administration. ${ }^{68}$ Principles of designing label formats for medication-error prevention have been proposed by the ISMP. Following the Joint Commission's recommendations regarding the use of two patient identifiers is exceedingly important in the ED to reduce medication errors. ${ }^{60}$ Having a system of double checks on high-alert medications (ie, those medications at an elevated risk of causing significant harm when involved in an error) is also a preventive measure to limit mistakes. ${ }^{69}$

If CPOE is not available, it is important to ensure that prescriptions are written clearly and legibly or to employ the use of prescription-writing software if available to reduce errors. ${ }^{6}$ In addition, using the same prescribing vocabulary on these prescriptions and only using generic medication names helps limit medication-name confusion. Also, listing indications on all prescriptions assists pharmacists and nurses in clarifying appropriateness. Limiting the use of acronyms and abbreviations can also assist in minimizing misinterpretation. ${ }^{70,71}$ In addition, ensuring that the prescriber's contact information is always listed on the prescription will aid in getting clarification if necessary. For all medication orders, instituting a system of double checks, particularly on calculations, and ensuring the weights used in these calculations are documented in kilograms and not pounds, has been shown to reduce errors significantly. ${ }^{6}$ Creating a system of safety checks is exceedingly important in the ED to ensure a system of redundant safeguards (Table 2).

\section{Education}

Strategies that target work structures and staff development have also been developed for reducing medication

Table 2 Safety checks for preventing medication errors

\begin{tabular}{|c|c|}
\hline Correct patient & $\begin{array}{l}\text { As most practitioners in the ED care for } \\
\text { multiple patients at the same time, it is critical to } \\
\text { ensure that the correct patient is being treated }\end{array}$ \\
\hline Correct drug & $\begin{array}{l}\text { Double-check that the drug is the correct } \\
\text { one, keeping in mind soundalike and lookalike } \\
\text { medications; confirm patient's allergy history }\end{array}$ \\
\hline Correct dosage & $\begin{array}{l}\text { Verify that the correct dosage, form, and route } \\
\text { of medication is being administered; confirm } \\
\text { proper placement of decimal points }\end{array}$ \\
\hline Compatibility & $\begin{array}{l}\text { Clarify that IV medications administered are } \\
\text { compatible; contacting a pharmacist to assist you } \\
\text { in this can be very helpful }\end{array}$ \\
\hline Double-check IV lines & $\begin{array}{l}\text { Ensure that the patient has adequate access for } \\
\text { IV administration, and that the appropriate line } \\
\text { (central versus peripheral) is being used }\end{array}$ \\
\hline Confirm arithmetic & $\begin{array}{l}\text { Having a second nurse or pharmacist double } \\
\text { check your arithmetic is very helpful }\end{array}$ \\
\hline $\begin{array}{l}\text { Correct route of } \\
\text { administration }\end{array}$ & Verify that the appropriate route is being utilized \\
\hline $\begin{array}{l}\text { Correct rate of } \\
\text { administration }\end{array}$ & $\begin{array}{l}\text { Ensure that you know the appropriate rate } \\
\text { of administration of the agent, and if you are } \\
\text { programming a pump that you double check } \\
\text { your programming }\end{array}$ \\
\hline $\begin{array}{l}\text { Correct patient } \\
\text { weight }\end{array}$ & Verify patient weight in kilograms \\
\hline
\end{tabular}

Abbreviations: ED, emergency department; IV, intravenous. Note: Data from Peth. ${ }^{6}$ 
errors. Having an insufficient knowledge base pertaining to medication use has been noted as a common root cause of medication-prescribing errors. The logarithmic increase in medications over the years has contributed significantly to the challenges presented to health care practitioners to be familiar with the multiple new drugs added to the spectrum every year. Each new drug presents its own set of potential ADEs and potential risk for medication errors. Additionally, educational interventions, such as the World Health Organization's Good Prescribing Guide, have improved the prescribing skills of students and junior physicians; however, little evidence exists linking these programs to changes in safety. ${ }^{72}$

One study examined a 3-month educational intervention entitled "Preventing Medication and IV Administration Errors" and compared pre- and postoutcome variables. ${ }^{73}$ This educational program described current medication errors in the ED, and recommended practices for reducing medication-administration errors. During the study, $75 \%$ of the nursing staff participated. The outcome variables measured included, 1) knowledge of medication-administration procedures assessed by tests, 2) behaviors reflecting recommended medication practices assessed by surveys, and 3) medication-administration errors, identified via chart review and voluntary error reports. The authors found a significant improvement on the knowledge test pre- and postintervention (69\% versus $92 \%$ ). This did not appear to translate into practice, however, as overall, medication errors were not shown to decrease significantly between the preand postintervention groups (44\% versus 34\%). However, there were two medication errors that did show a significant change: "IV fluids ordered but not given" (4.9\% versus $1.4 \%$ ) and "Incomplete documentation" (14\% versus 7.4\%). Despite this study's inability to translate education into medicationerror reduction directly, it did demonstrate that knowledge deficits do exist and can be significant. Furthermore, as the most common medication errors originate at the prescribing stage and involve dosing errors, education activities directed at physicians may prove more impactful at overall medication-error reduction.

In the absence of formal educational sessions, the utilization of alternative educational methods and quick-reference guides can be useful. One study randomized inexperienced pediatric physicians to receive a 1 - to 2-hour e-learning course or no education, and evaluated their prescribing habits 3 months out. ${ }^{74}$ They found a significant improvement in prescribing skills among the intervention group. Another study sought to look at computer-assisted prescribing in pediatric patients in an outpatient clinic, ED, and at discharge from the inpatient service. ${ }^{75}$ Prescribers had the choice of prescribing using the traditional method or a method of a computer-calculated dose. The authors found that utilization of the computer method reduced dosing errors from $28.2 \%$ to $12.6 \%$. The challenge with this approach, however, would be implementing such a system in an acute situation in the ED rather than strictly for discharge prescriptions.

This is an area where advocacy and education regarding medication-error reporting and care improvement can also have a profound impact. In one study that looked at the addition of two emergency-medicine pharmacists to a busy level 1 trauma center at a university teaching hospital, it was found that pharmacy personnel captured significantly more errors than other health care personnel $(94.5 \%$ versus $5.7 \%){ }^{76}$ The addition of two emergency-medicine pharmacists resulted in 14.8 times as many medication-error reports compared to the period when they were not present. Of note, this increase in reporting also had the collateral effect of increasing nursing staff reporting of medication errors by over $200 \%$ through increased education about error reporting and an emphasis on this activity. Another study looked at the impact of a resident physician educational series conducted on the first day of each month over a 3-month period. ${ }^{77}$ This education included a discussion of medication-error rates and ADE reporting, as well as patient case examples. In the analysis of the program, statistically significant declines in the number of dosage adjustments and order clarifications were noted by pharmacists. In addition, a statistically significant reduction in ADEs was observed. Although both of these studies were small, single-center experiences and therefore limited as to their specific generalizability, the need for education regarding medication-error reporting in the ED should most assuredly be a part of every institution's safety plan.

\section{Emergency-medicine clinical pharmacists}

The American Society of Health-System Pharmacists' statement on pharmacy services to the ED recommends that every hospital pharmacy "provide its emergency department (ED) with the pharmacy services that are necessary to support safe and effective patient care". ${ }^{78}$ In addition, the IOM's Committee on the Future of Emergency Care recommends ED pharmacists' inclusion in team approaches to improve ED medication safety and cost-effectiveness. ${ }^{2}$ As experts in safe medication use, pharmacists offer many opportunities to decrease the possibility of medication errors. Ideally, pharmacists should review and approve all nonemergent drug orders and then assist in preparing the final unit of use. 
A retrospective study of 490 medication orders found that ED pharmacists reduced medication errors by two-thirds, from 16.1 to 5.4 per 100 orders, correlating with the elimination of 10.7 medication errors per 100 orders. ${ }^{79}$ The greatest limitation with these impressive numbers, however, is the lack of correlation with clinical implications.

Another study conducted at four academic EDs documented ED pharmacists' activities to clarify this limitation further. Over a span of 787 hours of observation, it was found that pharmacists reviewed 17,320 medications and recovered 504 medication errors. ${ }^{80}$ This translates into 7.8 per 100 patients and 2.9 per 100 medications. The vast majority of the medication errors intercepted were potential ADEs $(90.3 \%)$, and the potential severities of the recovered errors were most often serious (47.8\%) or significant (36.2\%). The most common medication classes associated with recovered medication errors were antimicrobial agents $(32.1 \%)$, central nervous system agents (16.2\%), and anticoagulant and thrombolytic agents (14.1\%). The most common error types were dosing errors, drug omission, and wrong-frequency errors. While this study described the potential implications of the medication errors prevented, it fell short in describing what the pharmacist was specifically doing that made such a difference.

In order to investigate the specific activities that pharmacists participate in that contribute to medication-error interception in the $\mathrm{ED}$, a prospective, multicenter study was conducted at four US EDs. ${ }^{7}$ Over a total of 1,000 hours of recorded time and 16,446 patients seen, pharmacists intercepted 364 medication errors. The most common activities that contributed to medication-error interception were "involvement in consultative activities" (51.4\%) and "review of medication orders" (34.9\%). The most common types of order that resulted in medication-error interceptions were written or computerized orders (54.4\%) and verbal orders (32.7\%). Although these were self-reported activities, this study further demonstrated that clinical pharmacists in the ED can have a significant impact on medication-error interceptions. More importantly, it also demonstrated that it is imperative that they be present at the bedside and involved in direct patient care in order to be optimally effective. These evaluations also impart the importance of encouraging more prospective trials that convey how clinical pharmacists can impact outcomes related to medication errors in the ED setting.

\section{Conclusion}

The ED is a unique clinical practice environment that is especially at risk for the occurrence of medication errors. It is critical that institutions develop cultures that promote the reporting and correction of these errors in a systematic and nonpunitive fashion. Multiple strategies exist to decrease and mitigate these errors, including medication-error analysis, CPOE systems, automated dispensing cabinets, bar-coding systems, medication reconciliation, standardizing medication-use processes, education, and emergencymedicine clinical pharmacists. For those institutions that serve the pediatric population, it is also important to institute safeguards that provide additional protection for this particularly susceptible population. While the complete elimination of medication errors in the ED is an unrealistic goal, making their occurrence rare and not harmful is not.

\section{Disclosure}

The authors report no conflicts of interest in this work.

\section{References}

1. Aspden P, Wolcott J, Bootman L, Cronenwett LR. Preventing Medication Errors. Washington: National Academies; 2007.

2. Committee on the Future of Emergency Care in the United States Health System, Board on Health Care Services, Institute of Medicine. Hospital-Based Emergency Care: At the Breaking Point. Washington: National Academies; 2007.

3. Weingart SN, Wilson RM, Gibberd RW, Harrison B. Epidemiology of medical error. BMJ. 2000;320(7237):774-777.

4. Leape LL. Preventing adverse drug events. Am J Health Syst Pharm. 1995;52(4):379-382.

5. Bates DW, Boyle DL, Vander Vliet MB, Schneider J, Leape L. Relationship between medication errors and adverse drug events. J Gen Intern Med. 1995;10(4):199-205.

6. Peth HA Jr. Medication errors in the emergency department: a systems approach to minimizing risk. Emerg Med Clin North Am. 2003;21(1):141-158.

7. Patanwala AE, Sanders AB, Thomas MC, et al. A prospective, multicenter study of pharmacist activities resulting in medication error interception in the emergency department. Ann Emerg Med. 2012;59(5): 369-373.

8. Bates DW, Cullen DJ, Laird N, et al. Incidence of adverse drug events and potential adverse drug events. Implications for prevention. ADE Prevention Study Group. JAMA. 1995;274(1):29-34.

9. Leape LL, Brennan TA, Laird N, et al. The nature of adverse events in hospitalized patients. Results of the Harvard Medical Practice Study II. N Engl J Med. 1991;324(6):377-384.

10. Croskerry P, Shapiro M, Campbell S, et al. Profiles in patient safety: medication errors in the emergency department. Acad Emerg Med. 2004;11(3):289-299.

11. Schenkel S. Promoting patient safety and preventing medical error in emergency departments. Acad Emerg Med. 2000;7(11): 1204-1222.

12. Juarez A, Gacki-Smith J, Bauer MR, et al. Barriers to emergency departments' adherence to four medication safety-related Joint Commission national patient safety goals. Jt Comm J Qual Patient Saf. 2009;35(1): 49-59.

13. Pitts SR, Niska RW, Xu J, Burt CW. National Hospital Ambulatory Medical Care Survey: 2006 emergency department summary. Natl Health Stat Report. 2008;(7):1-38.

14. Pham JC, Story JL, Hicks RW, et al. National study on the frequency, types, causes, and consequences of voluntarily reported emergency department medication errors. J Emerg Med. 2011;40(5):485-492. 
15. Kaushal R, Bates DW, Landrigan C, et al. Medication errors and adverse drug events in pediatric inpatients. JAMA. 2001;285(16):2114-2120.

16. Committee on the Future of Emergency Care in the United States Health System, Board on Health Care Services, Institute of Medicine. Emergency Care for Children: Growing Pains. Washington: National Academies; 2007.

17. Selbst SM, Fein JA, Osterhoudt K, Ho W. Medication errors in a pediatric emergency department. Pediatr Emerg Care. 1999;15(1):1-4.

18. Koren G, Haslam RH. Pediatric medication errors: predicting and preventing tenfold disasters. J Clin Pharmacol. 1994;34(11): $1043-1045$.

19. Perlstein PH, Callison C, White M, Barnes B, Edwards NK. Errors in drug computations during newborn intensive care. Am J Dis Child. 1979;133(4):376-379.

20. Kaushal R, Jaggi T, Walsh K, Fortescue EB, Bates DW. Pediatric medication errors: what do we know? What gaps remain? Ambul Pediatr. 2004;4(1):73-81.

21. Leape LL. Institute of Medicine medical error figures are not exaggerated. JAMA. 2000;284(1):95-97.

22. Chin MH, Wang LC, Jin L, et al. Appropriateness of medication selection for older persons in an urban academic emergency department. Acad Emerg Med. 1999;6(12):1232-1242.

23. Kozer E, Scolnik D, Macpherson A, et al. Variables associated with medication errors in pediatric emergency medicine. Pediatrics. 2002;110(4):737-742.

24. Campbell SG, Croskerry P, Bond WF. Profiles in patient safety: a "perfect storm" in the emergency department. Acad Emerg Med. 2007;14(8):743-749.

25. Senst BL, Achusim LE, Genest RP, et al. Practical approach to determining costs and frequency of adverse drug events in a health care network. Am J Health Syst Pharm. 2001;58(12):1126-1132.

26. Leape LL, Bates DW, Cullen DJ, et al. Systems analysis of adverse drug events. ADE Prevention Study Group. JAMA. 1995;274(1):35-43.

27. Lesar TS, Briceland L, Stein DS. Factors related to errors in medication prescribing. JAMA. 1997;277(4):312-317.

28. Pham JC, Aswani MS, Rosen M, et al. Reducing medical errors and adverse events. Аnпи Rev Med. 2012;63:447-463.

29. Blum KV, Abel SR, Urbanski CJ, Pierce JM. Medication error prevention by pharmacists. Am J Hosp Pharm. 1988;45(9):1902-1903.

30. Folli HL, Poole RL, Benitz WE, Russo JC. Medication error prevention by clinical pharmacists in two children's hospitals. Pediatrics. 1987;79(5):718-722.

31. Thomas EJ, Studdert DM, Newhouse JP, et al. Costs of medical injuries in Utah and Colorado. Inquiry. 1999;36(3):255-264.

32. Committee on Quality of Health Care in America, Institute of Medicine, Kohn LT, Corrigan JM, Donaldson MS. To Err is Human: Building a Safer Health System. Washington: National Academies; 1999.

33. Zhan C, Smith SR, Keyes MA, Hicks RW, Cousins DD, Clancy CM. How useful are voluntary medication error reports? The case of warfarin-related medication errors. Jt Comm J Qual Patient Saf. 2008;34(1):36-45.

34. Rex JH, Turnbull JE, Allen SJ, Vande Voorde K, Luther K. Systematic root cause analysis of adverse drug events in a tertiary referral hospital. Jt Comm J Qual Improv. 2000;26(10):563-575.

35. National Coordinating Council for Medication Error Reporting and Prevention. NCC MERP index for categorizing medication errors. Available from: http://www.nccmerp.org/medErrorCatIndex.html. Accessed July 4, 2014.

36. Quantros, Inc. Medmarx database. Available from: http://www.medmarx. com. Accessed July 4, 2014.

37. Institute for Safe Medication Practices. Institute for Safe Medication Practices (ISMP) guidance on the interdisciplinary safe use of automated dispensing cabinets. 2008. Available from: http://www.ismp.org/Tools/ guidelines/ADC/default.asp. Accessed January 26, 2014.

38. Institute for Safe Medication Practices. Special error alerts. 2014. Available from: http://www.ismp.org/NAN/default.asp. Accessed February 17, 2014.
39. Bagian JP, Gosbee J, Lee CZ, Williams L, McKnight SD, Mannos DM. The Veterans Affairs root cause analysis system in action. Jt Comm J Qual Improv. 2002;28(10):531-545.

40. Duwe B, Fuchs BD, Hansen-Flaschen J. Failure mode and effects analysis application to critical care medicine. Crit Care Clin. 2005;21(1): 21-30, vii.

41. DeRosier J, Stalhandske E, Bagian JP, Nudell T. Using health care failure mode and effect analysis: the VA National Center for Patient Safety's prospective risk analysis system. Jt Comm J Qual Improv. 2002;28(5):248-267, 209.

42. de Koning H, Verver JP, van den Heuvel J, Bisgaard S, Does RJ. Lean six sigma in healthcare. $J$ Healthc Qual. 2006;28(2):4-11.

43. Ching JM, Long C, Williams BL, Blackmore CC. Using lean to improve medication administration safety: in search of the "perfect dose". Jt Comm J Qual Patient Saf. 2013;39(5):195-204.

44. Sard BE, Walsh KE, Doros G, Hannon M, Moschetti W, Bauchner H. Retrospective evaluation of a computerized physician order entry adaptation to prevent prescribing errors in a pediatric emergency department. Pediatrics. 2008;122(4):782-787.

45. Moniz TT, Seger AC, Keohane CA, Seger DL, Bates DW, Rothschild JM. Addition of electronic prescription transmission to computerized prescriber order entry: effect on dispensing errors in community pharmacies. Am J Health Syst Pharm. 2011;68(2):158-163.

46. Longhurst CA, Parast L, Sandborg CI, et al. Decrease in hospital-wide mortality rate after implementation of a commercially sold computerized physician order entry system. Pediatrics. 2010;126(1):14-21.

47. Swanson Kazley A, Diana ML. Hospital computerized provider order entry adoption and quality: an examination of the United States. Health Care Manage Rev. 2011;36(1):86-94.

48. Koppel R, Metlay JP, Cohen A, et al. Role of computerized physician order entry systems in facilitating medication errors. JAMA. 2005;293(10):1197-1203.

49. Shojania KG, Jennings A, Mayhew A, Ramsay C, Eccles M, Grimshaw J. Effect of point-of-care computer reminders on physician behaviour: a systematic review. CMAJ. 2010;182(5):E216-E225.

50. Maslove DM, Rizk N, Lowe HJ. Computerized physician order entry in the critical care environment: a review of current literature. $J$ Intensive Care Med. 2011;26(3):165-171.

51. Paparella S. Automated medication dispensing systems: not error free. J Emerg Nurs. 2006;32(1):71-74.

52. [No authors listed]. ASHP guidelines on the safe use of automated medication storage and distribution devices. American Society of Health-System Pharmacists. Am J Health Syst Pharm. 1998;55(13): 1403-1407.

53. Cochran GL, Jones KJ, Brockman J, Skinner A, Hicks RW. Errors prevented by and associated with bar-code medication administration systems. Jt Comm J Qual Patient Saf. 2007;33(5):293-301, 245.

54. Institute for Safe Medication Practices. ISMP's list of confused drug names. 2011. Available from: http://www.ismp.org/Tools/confuseddrugnames.pdf. Accessed February 17, 2014.

55. Poon EG, Keohane CA, Yoon CS, et al. Effect of bar-code technology on the safety of medication administration. $N$ Engl J Med. 2010;362(18): 1698-1707.

56. Cornish PL, Knowles SR, Marchesano R, et al. Unintended medication discrepancies at the time of hospital admission. Arch Intern Med. 2005;165(4):424-429.

57. Beers MH, Munekata M, Storrie M. The accuracy of medication histories in the hospital medical records of elderly persons. J Am Geriatr Soc. 1990;38(11):1183-1187.

58. Lau HS, Florax C, Porsius AJ, De Boer A. The completeness of medication histories in hospital medical records of patients admitted to general internal medicine wards. Br J Clin Pharmacol. 2000;49(6): 597-603.

59. Chisholm-Burns MA, Kim Lee J, Spivey CA, et al. US pharmacists' effect as team members on patient care: systematic review and meta-analyses. Med Care. 2010;48(10):923-933. 
60. Joint Commission. 2014 National patient safety goals. 2014. Available from: http://www.jointcommission.org/standards_information/npsgs. aspx. Accessed February 17, 2014

61. Pronovost P, Weast B, Schwarz M, et al. Medication reconciliation: a practical tool to reduce the risk of medication errors. J Crit Care. 2003;18(4):201-205.

62. Schnipper JL, Hamann C, Ndumele CD, et al. Effect of an electronic medication reconciliation application and process redesign on potential adverse drug events: a cluster-randomized trial. Arch Intern Med. 2009;169(8):771-780.

63. Karapinar-Carkit F, Borgsteede SD, Zoer J, Smit HJ, Egberts AC, van den Bemt PM. Effect of medication reconciliation with and without patient counseling on the number of pharmaceutical interventions among patients discharged from the hospital. Ann Pharmacother. 2009;43(6):1001-1010.

64. Fontan JE, Maneglier V, Nguyen VX, Loirat C, Brion F. Medication errors in hospitals: computerized unit dose drug dispensing system versus ward stock distribution system. Pharm World Sci. 2003;25(3): $112-117$.

65. Institute for Safe Medication Practices. Standard concentrations of neonatal drug infusions. 2011. Available from: http:/www.ismp.org/ Tools/PediatricConcentrations.pdf. Accessed February 17, 2014.

66. Filik R, Price J, Darker I, Gerrett D, Purdy K, Gale A. The influence of tall man lettering on drug name confusion: a laboratory-based investigation in the UK using younger and older adults and healthcare practitioners. Drug Saf. 2010;33(8):677-687.

67. Practices IfSM. FDA and ISMP Lists of Look-Alike Drug Names with Recommended Tall Man Letters. 2011; http://www.ismp.org/Tools/ tallmanletters.pdf. Accessed February 17, 2014.

68. Institute for Safe Medication Practices. Label formats finalized versions. 2014. Available from: http://www.ismp.org/Tools/guidelines/ labelFormats/default.asp. Accessed February 17, 2014.

69. Institute for Safe Medication Practices. ISMP's list of high-alert medications. 2012. Available from: http://www.ismp.org/Tools/ institutionalhighAlert.asp. Accessed February 17, 2014.
70. Joint Commission. Facts about the official "Do Not Use" list. 2013. Available from: http://www.jointcommission.org/assets/1/18/Do_Not_ Use_List.pdf. Accessed February 17, 2014.

71. Institute for Safe Medication Practices. ISMP's list of error-prone abbreviations, symbols, and dose designations. 2013. Available from: http:// www.ismp.org/Tools/errorproneabbreviations.pdf. Accessed February $17,2014$.

72. World Health Organization. Guide to Good Prescribing: A Practical Manual. Geneva: WHO; 1996.

73. Blank FS, Tobin J, Macomber S, Jaouen M, Dinoia M, Visintainer P. A "back to basics" approach to reduce ED medication errors. J Emerg Nurs. 2011;37(2):141-147.

74. Gordon M, Chandratilake M, Baker P. Improved junior paediatric prescribing skills after a short e-learning intervention: a randomised controlled trial. Arch Dis Child. 2011;96(12):1191-1194.

75. Kirk RC, Li-Meng Goh D, Packia J, Min Kam H, Ong BK. Computer calculated dose in paediatric prescribing. Drug Saf. 2005;28(9):817-824.

76. Weant KA, Humphries RL, Hite K, Armitstead JA. Effect of emergency medicine pharmacists on medication-error reporting in an emergency department. Am J Health Syst Pharm. 2010;67(21):1851-1855.

77. Foster ME, Lighter DE, Godambe AV, Edgerson B, Bradley R, Godambe $\mathrm{S}$. Effect of a resident physician educational program on pediatric emergency department pharmacy interventions and medication errors $J$ Pediatr Pharmacol Ther. 2013;18(1):53-62.

78. [No authors listed]. ASHP statement on pharmacy services to the emergency department. Am J Health Syst Pharm. 2008;65:2380-2383.

79. Brown JN, Barnes CL, Beasley B, Cisneros R, Pound M, Herring C. Effect of pharmacists on medication errors in an emergency department. Am J Health Syst Pharm. 2008;65(4):330-333.

80. Rothschild JM, Churchill W, Erickson A, et al. Medication errors recovered by emergency department pharmacists. Ann Emerg Med 2010;55(6):513-521.
Open Access Emergency Medicine

\section{Publish your work in this journal}

Open Access Emergency Medicine is an international, peer-reviewed, open access journal publishing original research, reports, editorials, reviews and commentaries on all aspects of emergency medicine. The manuscript management system is completely online and includes a very quick and fair peer-review system, which is all easy to use.

\section{Dovepress}

Visit http://www.dovepress.com/testimonials.php to read real quotes from published authors. 